\title{
Which Literacy Skills are Associated with Smoking?
}

\author{
Laurie T. Martin, ScD MPH ${ }^{1}$, Ann Haas, MS ${ }^{1}$, Matthias Schonlau, $\mathrm{PhD}^{1}$, Kathryn Pitkin \\ Derose, PhD, MPH ${ }^{1}$, Lindsay Rosenfeld, ScD ScM ${ }^{4}$, Rima Rudd, ScD ${ }^{2}$, and Stephen L. \\ Buka, ScD ${ }^{3}$ \\ ${ }^{1}$ RAND Corporation: Arlington, VA \\ ${ }^{2}$ Harvard School of Public Health: Boston, MA \\ ${ }^{3}$ Brown University School of Public Health: Providence, RI \\ ${ }^{4}$ Northeastern University: Boston, MA
}

\begin{abstract}
Background-Research has demonstrated associations between smoking and reading skills, but other literacy skills such as speaking, listening and numeracy are less studied despite our dependence on the use of numbers and the oral exchange to deliver information on the risks of smoking.

Methods-We used multivariable logistic regression to examine the effects of reading, numeracy, speaking and listening skills on 1) becoming a regular smoker and 2) smoking cessation. Further, multivariable linear regression was used to examine the relation between literacy skills and amount smoked among current smokers. Models controlled for education, gender, age, race/ethnicity, income, and, when relevant, age they became a regular smoker.
\end{abstract}

Results-For each grade equivalent increase in reading skills, the odds of quitting smoking increased by about $8 \%(\mathrm{OR}=1.08,95 \% \mathrm{CI}: 1.01-1.15)$. For every point increase in numeracy skills, the odds of quitting increased by about $24 \%(\mathrm{OR}=1.24,95 \% \mathrm{CI}$ : $1.06-1.46)$. No literacy skills were associated with becoming a regular smoker or current amount smoked.

Conclusion-The ability to locate, understand and use information related to the risks of smoking may impact one's decision to quit. Messaging should be designed with the goal of being easily understood by all individuals regardless of literacy level.

\section{Keywords}

COMMUNICATION; HEALTH POLICY; PUBLIC HEALTH EPIDEMIOLOGY; PUBLIC HEALTH POLICY; SMOKING

\section{Introduction}

Although both population-based and clinical interventions have been successful in lowering rates of cigarette smoking in the U.S. over time, the prevalence of smoking remains

Corresponding Author: Laurie Martin, RAND Corporation, 1200 South Hayes Street, Arlington, VA 22202, Tel: (703) 413-1100× 5083, Fax: (703.413.8111, lamartin@ rand.org.

License Statement: The Corresponding Author has the right to grant on behalf of all authors and does grant on behalf of all authors, an exclusive licence (or non-exclusive for government employees) on a worldwide basis to the BMJ Publishing Group Ltd and its Licensees to permit this article (if accepted) to be published in Journal of Epidemiology and Community Health and any other BMJPGL products to exploit all subsidiary rights, as set out in our licence

(http://group.bmj.com/products/journals/instructions-for-authors/wholly_owned_licence.pdf). 
considerably higher than the Healthy People 2020 objective of $12 \% .{ }^{1}$ Achieving this goal requires a rethinking of strategies to reduce smoking uptake and increase smoking cessation. Understanding the role of literacy skills in smoking uptake and cessation may provide important insight.

Several studies have identified an inverse association between reading skills and cigarette smoking. ${ }^{2-6}$ Other skills such as oral language (speaking), aural language (listening) and numeracy are less studied, despite our dependence on the oral exchange to communicate options for smoking cessation and use of numbers to deliver information on the risks of smoking.

The objective of the current study was to use a large community-based sample to evaluate the individual and combined effects of reading, numeracy, speaking and listening skills on 1) becoming a regular weekly smoker, 2) smoking cessation among regular smokers, and 3) the amount of cigarettes smoked among current smokers. Identifying which skill(s) are most strongly associated with smoking-related decisions may help stakeholders develop and deliver messaging that is clear, informative, and actionable.

\section{Methods}

\section{Study Population}

Participants were adult offspring of pregnant women enrolled in the National Collaborative Perinatal Project (NCPP) between 1959 and $1966 .{ }^{7}$ In 2001, the New England Family Study (NEFS) was established to locate and interview the now-adult cohorts of the Providence, Rhode Island and Boston, Massachusetts NCPP sites. As part of the NEFS, a stratified random sample of 914 participants in their mid 40s was selected for a study

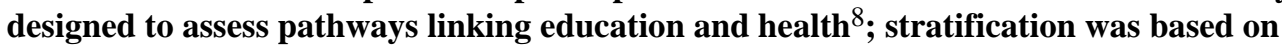
educational attainment. A total of 618 respondents $(67.6 \%)$ were successfully located and interviewed. This assessment was approved by the Human Subjects Protection Committee of the Harvard School of Public Health.

Measures

Health literacy-Speaking was assessed by the WJ III achievement test "Story Recall," in which participants listen to a pre-recorded short story and are then asked to repeat the story back to the interviewer. Scores are based on the correct number of words or phrases repeated. ${ }^{9}$ Grade equivalent scores were used for oral language, aural language and reading and ranged from kindergarten (when children are 5 or $\mathbf{6}$ years of age) to greater than 18.0 years of education (i.e., an advanced degree).

Listening was assessed by the WJ III achievement test "Understanding Directions," in which participants are given an illustrated drawing and are asked to follow pre-recorded directions to point to objects in the picture. Difficulty increases as drawings become more complex and the tasks increase in number of components. Scores are based on the number of correct tasks completed. Reliability and validity for these tests of achievement are good: For "Story Recall" and "Understanding Directions", the one year test-rest reliability was 0.70 and 0.88 , respectively. ${ }^{9}$

Reading comprehension was assessed using the "Passage Comprehension" test from the WJ III Tests of Achievement, where individuals fill in missing words from a sentence from a list of multiple choice answers. Reliability and validity for this test are also good; the one-year test-retest reliability was $0.92 .{ }^{9}$ 
Numeracy was assessed using eight items from the scale developed by Lipkus and colleagues. ${ }^{1011}$. Three items were dropped from the Lipkus scale (item number 2 from the general numeracy scale, and items 3 and 7 from the expanded numeracy scale) due to time constraints for the full protocol. Analogously to Lipkus ${ }^{10}$ we conducted a factor analysis using the $8 \times 8$ matrix of tetrachoric correlations on this shortened scale, used to assess the correlation among dichotomous variables. Factor analysis confirmed a one-factor solution, with all 8 items loading on the first factor (individual loadings each exceeded 0.4). The first factor accounted for $86.25 \%$ of the variance. Numeracy scores were based on the total number of correct responses (range: $0-8$, mean $=5.47, \mathrm{SD}=1.85$ ).

Smoking-Participants were classified as an ever-regular smoker if they reported that they had ever smoked at least once per week for two months or longer. Ever-regular smokers were further classified into current smokers and former smokers, based on their response to the question "Do you smoke cigarettes now?" Current smokers also reported how many cigarettes they smoked per day; this number was log transformed in analyses to satisfy regression assumptions.

Demographic predictors-Educational attainment was transformed into the number of years of formal schooling ranging from 7-21 years, and had a low to moderate correlation with reading $(0.43)$, numeracy $(0.42)$, listening $(0.33)$ and speaking $(0.28)$. Annual income was categorized as $<\$ 20,000, \$ 20,000-60,000$, and greater than $\$ 60,000$. Race/ ethnicity (i.e., non-Hispanic white, non-Hispanic Black, Hispanic/other), age, and gender were self-reported.

\section{Missing values and imputation}

Six individuals were missing current smoking status and were excluded from all analysis. A total of 112 individuals ( $18.3 \%$ of sample) had missing values for at least one covariate. Missing values were multiply (five times) imputed in STATA 11 using the ICE (Imputation by Chained Equations) package. ${ }^{12}$ Imputation did not significantly change the demographic makeup of the sample or range of literacy skills.

\section{Analysis}

We used multivariable logistic regression to assess the individual, combined, and interactive associations between literacy skills and ever-regular smoking, and between literacy skills and quitting smoking. We used multivariable linear regression to examine the association between literacy skills and log number of cigarettes per day among smokers. Models were first fit with each literacy skill individually, and then all four skills were examined simultaneously. Given that the sample contained siblings, regression models contained random intercepts to account for clustering within families. Regression models were computed separately for each imputed dataset and the results were combined across imputations according to Rubin's rule. ${ }^{12}$ Analyses were adjusted for education, race/ ethnicity, gender, income, and age. For analyses of smoking cessation and current amount smoked, age at smoking onset was also included as a covariate.

\section{Results}

Table 1 presents the sociodemographic characteristics and literacy skills among current smokers, former smokers (those who have quit) and never regular smokers. The sample contains $27.1 \%$ current smokers, $29.6 \%$ former smokers, and $43.3 \%$ never-regular smokers.

No literacy skills were associated with becoming a regular smoker or the number of cigarettes smoked among current smokers. However, both reading and numeracy were 
significantly associated with smoking cessation among those who had ever been regular smokers (Table 2). For each grade equivalent increase in reading, the odds of quitting smoking increased by about $8 \%(\mathrm{OR}=1.08,95 \% \mathrm{CI}$ : $1.01-1.15)$. For every point increase on the numeracy scale, the odds of quitting increased by about $24 \%$ (OR=1.24, 95\%CI: $1.06-$ 1.46). When examined simultaneously, neither reading (OR=1.06, 95\%CI: $0.98,1.15$, $\mathrm{p}=0.13)$ nor numeracy $(\mathrm{OR}=1.19,95 \% \mathrm{CI}: 0.99-1.43, \mathrm{p}=0.06)$ remained statistically significant, although a joint test of reading and numeracy, excluding measures of speaking and listening from the model, was significant (Wald $\chi^{2}=8.98 ; \mathrm{p}=0.01$ ).

\section{Discussion}

Both reading and numeracy were significantly and positively associated with successful smoking cessation. These findings suggest that how well one is able to locate, understand and use information related to the risks of smoking may impact his or her decision to quit. As a result, more attention may need to be paid in how we relay such information to current smokers to ensure that the messages are easily understood and actionable by all individuals regardless of literacy level.

This study provides important insight for further research and practice. Materials designed to inform the population about the dangers of smoking and options for smoking cessation support should be written using plain language standards ${ }^{13}$, which is understood better and appreciated by the majority of individuals, regardless of literacy level. ${ }^{14-16}$ Newer intervention strategies such as the use of text messaging ${ }^{17}$ and emails ${ }^{18}$ also draw heavily on reading skills and should be tested and developed with the literacy skills of participants in mind. More work is also needed on how to most effectively communicate the concepts of risk to the general population to help in the decision not only to quit, but to understand the probability of success or relapse for the various smoking cessation methods available.

There are several limitations of this study worth noting. The sample consists of individuals living in Providence, RI and Boston, MA and as a result, may not be generalizable. All respondents were born in the United States, and the interviews were conducted in English. Our study is also cross sectional; causality cannot be assumed. While our measures were used to approximate health literacy skills, the skills themselves were not assessed within a health context and, thus, cannot be considered measures of health literacy.

Our findings suggest a need to better understand the association between a wide range of literacy skills and smoking status. More work is also needed to understand the mechanisms behind the association, which may have important implications for the development of prevention and cessation strategies and for clear communication about the risks of smoking.

\section{References}

1. U.S. Department of Health and Human Services. Healthy People 2020: Tobacco Use Objectives. Washington, DC: U.S. Department of Health and Human Services; 2010.

2. Hawthorne G. Preteenage drug use in Australia: the key predictors and school-based drug education. J Adolesc Health. 1996; 20:384-95. [PubMed: 9168386]

3. Fredrickson D, Washington R, Pham N, Jackson T, Wiltshire J, Jecha L. Reading grade levels and health behaviors of parents at child clinics. Kansas Med. 1995; 96:127-29.

4. Arnold C, Davis TC, Berkel H, Jackson R, Nandy I, London S. Smoking status, reading level, and knowledge of tobacco effects among low-income pregnant women. Prev Med. 2001; 32:313-20. [PubMed: 11304092]

5. Baker DW, Wolf MS, Feinglass J, Thompson JA, Gazmararian JA, Huang J. Health Literacy and Mortality Among Elderly Persons. Arch Intern Med. 2007; 167(14):1503. [PubMed: 17646604] 
6. Sudore R, Yaffe K, Satterfield S, Harris T, Mehta K, Simonsick E, et al. Limited literacy and mortality in the elderly. J Gen Intern Med. 2006; 21:806-12. [PubMed: 16881938]

7. Niswander, K.; Gordon, M. The Women and Their Pregnancies. Washington, DC: U.S. Government Printing Office; 1972.

8. Gilman S, Martin L, Abrams D, Kawachi I, Kubzansky L, Loucks E, et al. Educational attainment and smoking: A causal association? Int J Epidemiol. 2008; 37(3):615-24. [PubMed: 18180240]

9. Woodcock, RW.; McGrew, KS.; Mather, N. Technical Manual Woodcock-Johnson III. Itasca, IL: Riverside Publishing; 2001.

10. Lipkus IM, Samsa G, Rimer BK. General Performance on a Numeracy Scale among Highly Educated Samples. Med Decis Making. 2001; 21(1):37. [PubMed: 11206945]

11. Schwartz L, Woloshin S, Black W, Welch G. The role of numeracy in understanding the benefit of screening mammography. Ann Intern Med. 1997; 127:966-71. [PubMed: 9412301]

12. Royston P. Multiple imputation of missing values. Stata Journal. 2004; 4:227-41.

13. Doak, C.; Doak, L.; Root, J. Teaching patients with low literacy skills. 2. Philadelphia: J.B. Lippincott; 1996.

14. Gerber BS, Brodsky IG, Lawless KA, Smolin LI, Arozullah AM, Smith EV, et al. Implementation and evaluation of a low-literacy diabetes education computer multimedia application. Diabetes Care. 2005; 28(7):1574-80. [PubMed: 15983303]

15. Kripalani S, Robertson R, Love-Ghaffari MH, Henderson LE, JP, Strawder A, et al. Development of an illustrated medication schedule as a low-literacy patient education tool. Patient Educ Couns. 2007; 66(3):368-77. [PubMed: 17344015]

16. Sudore RL, Landefeld CS, Barnes DE, Lindquist K, Williams BA, Brody R, et al. An advance directive redesigned to meet the literacy level of most adults: A randomized trial. Patient Educ Couns. 2007; 69(1-3):165-95. [PubMed: 17942272]

17. Rodgers A, Corbett T, Bramley D, Riddell T, Wills M, Lin R-B, et al. Do u smoke after txt? Results of a randomized trial of smoking cessation using mobile phone text messaging. Tob Control. 2005; 14:255-61. [PubMed: 16046689]

18. Lenert L, Munoz R, Perez J, Bansod A. Automated e-mail messaging as a tool for improving quit rates in an internet smoking cessation intervention. J Am Med Inform Assoc. 2004; 11(4):235-40. [PubMed: 15064291] 
Table 1

Sample Characteristics for the Full Sample, Current Smokers, Former Smokers and those who have Never Smoked.

\begin{tabular}{|c|c|c|c|c|}
\hline & \multirow[t]{2}{*}{ Full Sample } & \multicolumn{2}{|c|}{ Regular Smoker } & \multirow[t]{2}{*}{ Never Regular Smoker } \\
\hline & & Current & Former & \\
\hline $\mathrm{N}$ & 612 & 166 & 181 & 265 \\
\hline Age, years & $42.5(1.8)$ & $42.3(1.9)$ & $42.6(2.0)$ & $42.5(1.7)$ \\
\hline Education, years & $13.6(2.6)$ & $12.5(2.1)$ & $13.6(2.4)$ & $14.4(2.7)$ \\
\hline \multicolumn{5}{|l|}{ Race } \\
\hline White & $78.1 \%$ & $75.9 \%$ & $80.7 \%$ & $77.7 \%$ \\
\hline Black & $16.7 \%$ & $19.3 \%$ & $13.3 \%$ & $17.4 \%$ \\
\hline Hispanic/other & $5.2 \%$ & $4.8 \%$ & $6.1 \%$ & $4.9 \%$ \\
\hline Male & $39.5 \%$ & $33.1 \%$ & $34.8 \%$ & $46.8 \%$ \\
\hline \multicolumn{5}{|l|}{ Income category } \\
\hline Less than 20,000 & $10.0 \%$ & $20.7 \%$ & $6.6 \%$ & $5.7 \%$ \\
\hline $20,000-60,000$ & $37.8 \%$ & $48.2 \%$ & $33.2 \%$ & $34.5 \%$ \\
\hline More than 60,000 & $52.2 \%$ & $31.1 \%$ & $60.2 \%$ & $59.9 \%$ \\
\hline \multicolumn{5}{|l|}{ Literacy Skills 1} \\
\hline Reading & $12.5(4.8)$ & $10.3(4.6)$ & $13.2(4.7)$ & $13.4(4.6)$ \\
\hline Numeracy & $5.5(1.9)$ & $4.7(1.9)$ & $5.8(1.7)$ & $5.7(1.8)$ \\
\hline Speaking & $7.7(4.4)$ & $6.9(4.2)$ & $7.8(4.1)$ & $8.1(4.7)$ \\
\hline Listening & $7.9(4.3)$ & $6.7(4.2)$ & $8.3(4.3)$ & $8.4(4.2)$ \\
\hline \multicolumn{5}{|l|}{ Smoking status } \\
\hline Current & $27.1 \%$ & & & \\
\hline Former & $29.6 \%$ & & & \\
\hline Never & $43.3 \%$ & & & \\
\hline Began smoking at $18+$ & & $17.7 \%$ & $24.6 \%$ & \\
\hline
\end{tabular}

${ }^{1}$ Reading, speaking and listening were scored on a continuous scale as grade equivalents, range K.0 (kindergarten, at 5 years of age) to >18.0 (18 years of education). Numeracy was scored on a continuous scale, range 0 to 8 . 
守

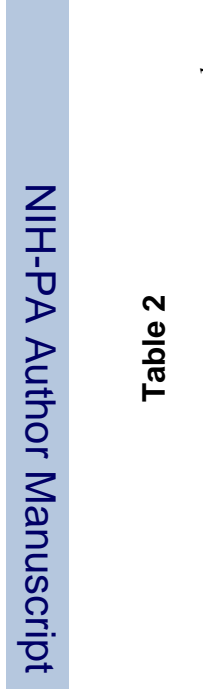

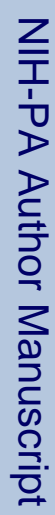

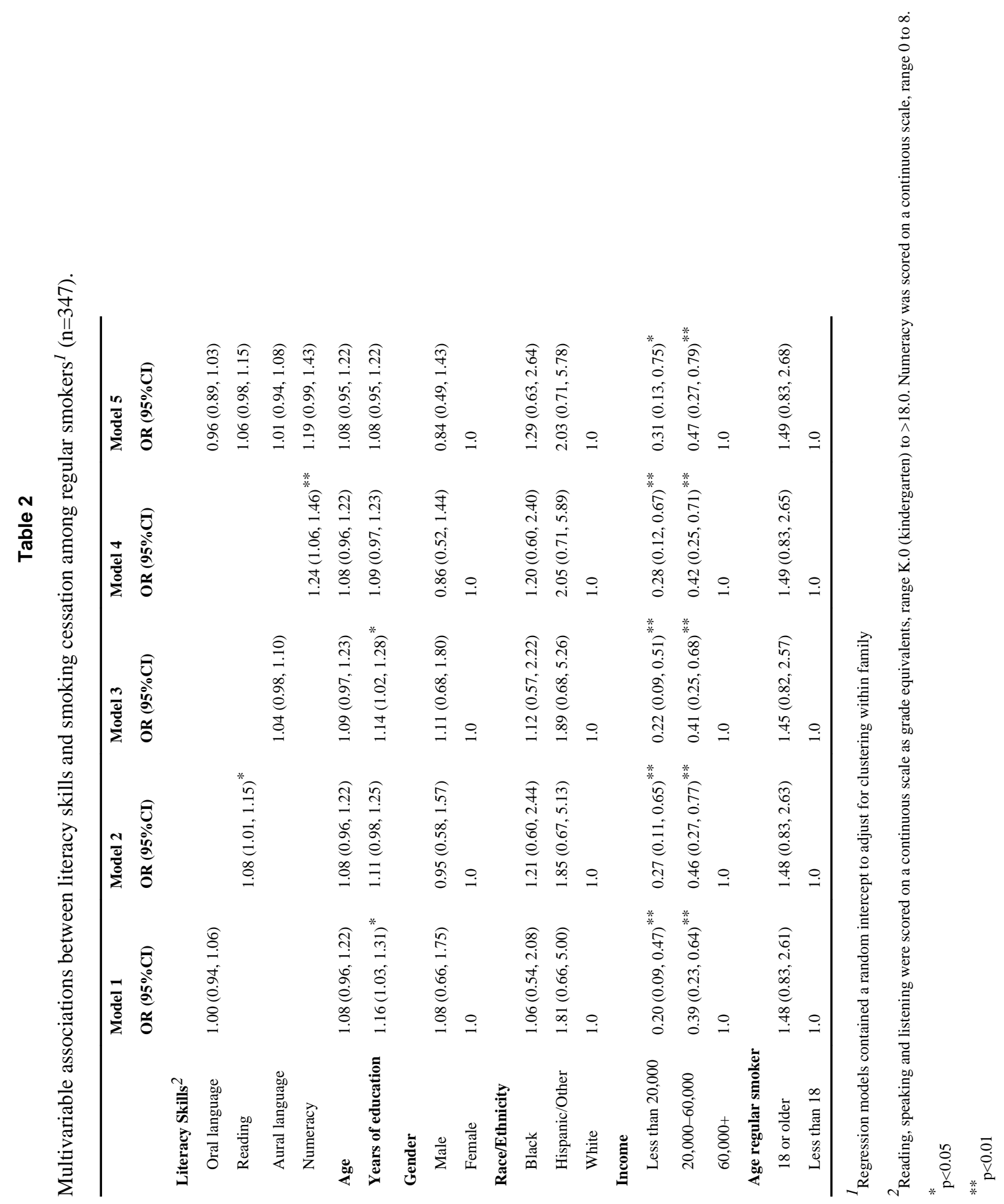

J Epidemiol Community Health. Author manuscript; available in PMC 2012 February 1. 